\title{
Design of a High Pressure Rig for Biaxial and Triaxial Compression Testing of Composite Tubes
}

\author{
A.S. Kaddour and P.D. Soden \\ Pariser Building, AppliedMechanics Division, UMIST, \\ P.O. Box 88, Sackville Street, Manchester, M60 IQD, U.K.
}

\section{SUMMARY}

This paper describes the design and use of a new highpressure rig for testing composite tubes under biaxial and triaxial compressive loading. The rig, which has a design pressure of $200 \mathrm{MPa}$, is capable of applying simultaneously well controlled ratios of external radial pressure, internal radial pressure and axial compressive load. The test specimens were designed to ensure fracture within the test section and to avoid structural instability. Preliminary experiments on thick $\pm 55^{\circ}$ filament-wound E-Glass/epoxy tubes are reported.

\section{NOMENCLATURE}

\section{D,d Diameter}

E Modulus of elasticity

F Measured axial force

h Thickness

L Length

$P \quad$ Pressure

R Radius

SR Ratio of circumferential stress to axial stress

$\varepsilon \quad$ Strain

$\sigma \quad$ Stress

$v \quad$ Poisson's ratio

\begin{tabular}{|c|c|}
\hline \multicolumn{2}{|c|}{ Subscripts } \\
\hline bu & Buckling \\
\hline cr & Crushing \\
\hline i,o & Inside and outside \\
\hline$\theta, \mathrm{x}$ & Hoop and axial direction \\
\hline
\end{tabular}

\section{INTRODUCTION}

Fibre-reinforced composites are frequently considered for applications where they will be subjected to large biaxial and triaxial compressive stresses. Thin tubular specimens are widely employed to study failure under combined internal pressure and axial loading $/ 1,2 /$. However, employing thin tubular specimens to study biaxial compressive strength under external pressure and axial loading was not successful, as structural instability or buckling rather than crushing was observed to be dominant $/ 3-8 /$. In addition, a number of investigators have studied the effect of superposed hydrostatic pressure on the compressive failure of composites using small specimens subjected to pressures up to $300 \mathrm{MPa}$ /9-13/. In these latter studies, high pressure cells of small dimensions were developed to test cylindrical solid bars of $1-5 \mathrm{~mm}$ diameter and no stress strain curves were provided. Shin and Pae /14, 15/ designed and developed a high pressure rig for testing small composite tubes under torsion at hydrostatic pressures up to $600 \mathrm{MPa}$. The tubes were made of carbon/epoxy material and were $1.5 \mathrm{~mm}$ inner diameter and up to $3 \mathrm{~mm}$ outer diameter. Recently, Jee and Swanson $/ 16 /$ studied the effect of superimposed pressure on the axial compressive strength of thin composite tubes of $50 \mathrm{~mm}$ diameter under values of pressure, up to $70 \mathrm{MPa}$, using the rig described previously $/ 6 /$. Kroll and Hufenbach $/ 17 /$ reported the existence of a high pressure chamber for hydrostatic pressure tests up to $600 \mathrm{MPa}$. 
It appears either that the existing test rigs are incapable of delivering very high external pressures or that the rigs are capable of applying high hydrostatic pressures, but the specimens are small and the variety of triaxial stress systems that can be applied is limited. Furthermore, in the existing high pressure cells, stressstrain curves were rarely measured.

There is a paucity of experimental data on failure under biaxial and triaxial compression. The lack of data can be attributed partly to the fact that it is not easy to design suitable test rigs and procedures.

This paper provides details of a multi-purpose high pressure rig for fracturing thick composite tubes under biaxial and triaxial compressive stress ratios at pressures of up to $200 \mathrm{MPa}$. Results of preliminary experiments on $\pm 55^{\circ}$ glass/epoxy filament-wound tubes tested to fracture are reported.

\section{PRELIMINARY CONSIDERATIONS FOR SPECIMEN DESIGN}

Tubular specimens are proposed to investigate the strength of filament-wound composite structures under biaxial and triaxial compressive loadings by applying a combination of external pressure, internal pressure and axial compression. However, in order to obtain the material strengths, the specimen should be designed so that failure takes place with no structural instability or end problems. General guide lines are presented below for calculating the required dimensions of orthotropic tubular specimens.

\section{Specimen Thickness}

The thickness of the tubular specimens should be chosen so that buckling is avoided. The external pressure at which a long thin orthotropic cylindrical tube buckles under radial external pressure loading may be estimated as $/ 8 /$

$$
P_{b u}=\frac{E_{\theta}}{4\left(1-v_{x \theta} v_{\theta x}\right)}\left(\frac{h}{R}\right)^{3}
$$

where $E_{\theta}$ is the hoop modulus, $v_{\theta x}, v_{x \theta}$ are Poisson's ratios and $h / R$ is the ratio of thickness to radius of the tubes.
The pressure at which circumferential crushing occurs at a hoop strength of $\sigma_{\theta}$ is given, from shell theory, as

$$
P_{c}=\sigma_{\theta}\left(\frac{h}{R}\right)
$$

In order to ensure failure with no buckling, the buckling pressure should be greater than the crushing pressure, i.e.,

$$
\frac{h}{R} \geq \sqrt{\frac{4 \sigma_{\theta}}{\underline{F}_{\theta}}\left(1-v_{\theta x} v_{x \theta}\right)}
$$

The addition of compressive axial stresses to filament wound tubes under circumferential compression is not expected to change the buckling pressure greatly but the crushing strengths $\left(\sigma_{\theta}\right)$ are expected to change considerably $/ 4 /$.

Shell buckling of thin walled cylinders under axial compressive load is sensitive to imperfections in shell geometry. Soden et al. /2/ have presented experimental results for filament-wound tubes which show values of $h / R$ required to ensure crushing rather than shell buckling under axial loading. Comparing those results with predictions from Eq. (3) indicates that the wall thickness chosen to avoid buckling under external pressure should also avoid buckling under axial load.

\section{Specimen Length}

Eq. (1) refers to very long tubes. Shorter tubes are expected to buckle at higher pressures but crushing pressures are not expected to be very different from those of long tubes $/ 8 /$.

End effects can arise which introduce local shell bending stresses. The test section of an orthotropic tube should have a length of at least

$$
L \geq \frac{2 \pi \sqrt{R h}}{\sqrt[4]{\frac{3 E_{\hat{x}}}{E_{x}}\left(1-v_{\theta x} v_{x \theta}\right)}}
$$

if the central section is to be unaffected by end effects $/ 18 /$. 


\section{End Reinforcement}

Discontinuity in loading (e.g., at seals in pressurized tubes) also produces local shell bending which can cause end failures. Previous experience has shown that it is necessary to thicken the ends of some tubular specimens locally to avoid end failure /18/. A finite element analysis was carried out to study the stress distribution along the reinforced tubes subjected to biaxial compression and to establish a suitable form of end reinforcement to strengthen the ends without introducing significant stress concentration $/ 19 /$.

\section{HIGH PRESSURE TEST RIGS}

The data sought are those shown in the schematic failure envelope in Fig. 1 which shows axial strength plotted against circumferential (hoop) strength for various combinations of biaxial or triaxial compressive stresses. The failure points at and between "a", " $b$ ", "c", " $d$ ", " $e$ " and "f" are achieved by subjecting tubes to combinations of external pressure, axial compression and internal pressure (lower than the external pressure). The three distinct points marked as "a", "b", " $c$ " are obtained without using internal pressure. Point "a", with a ratio of circumferential to axial stresses (SR) of $-1: 0$, requires the application of external radial pressures which results in compressive circumferential stress but with no axial loading. For point " $b$ ", with SR $=-2:-1$, the external pressure is equal to the end pressure. Point "c" corresponds to axial compressive loading only, with $S R=0:-1$ and no pressure involved.

To introduce a through-thickness stress component which is independent of the in-plane stresses it is proposed to apply equal pressures at the inner and outer surfaces of the tubes. Furthermore, to introduce a through-thickness stress component in combination with in-plane stresses, the tests require applying a difference between the internal and external pressures to achieve failure at and between points " $d$ ", " $e$ " and " $f$ " in Fig. 1. These types of tests involve applying internal pressure, external pressure and axial loads. The ratio of the internal pressure and external pressure is kept constant in any given test.
Figs. 2 and 3 show rigs capable of producing various stress ratios (SR). Friction forces of unmeasured magnitude arise if a seal is placed between the area of load application and the load measuring device. Efforts have been made, wherever possible, to obtain results which do not involve friction; a task that was not always feasible. Therefore, the following types of tests were proposed:

- External pressure tests for $\mathrm{SR}=-2:-1$ with no friction using the test arrangements shown in Fig. 2(a).

- External pressure with measured axial compression force $F$ acting to reduce the pressure end load with no friction, for $-6:-1<$ SR $<-2:-1$, Fig. 2(b).

- External pressure with axial tension for $-2:-1<\mathrm{SR}$ $<0$ :-1 with no friction, Fig. 2(c).

- External pressure and internal pressure for $\mathrm{SR} \approx-$ 2:-1 with no friction, Fig. 2(d).

- External pressure, internal pressure and axial loading for various values of SR, Fig. 2(E). Friction is involved in this case unless the load cell is located in the loading rod inside the pressure chamber. In our tests the load $\mathrm{F}$ was measured outside the pressure chamber.

The higher value of SR for the rig shown in Fig. 2(b) is stated as $-6:-1$ rather than $-1: 0$ because there is a pressure end load which acts on the tube wall thickness giving a stress ratio of approximately $\mathrm{SR}=$ -(PR/h):-P. The axial load could be eliminated by applying end grips which could transmit tensile loads to the specimen.

\section{Description of Rig Components}

The main components in these rigs (Fig. 2) are

- A thick cylindrical vessel, item 1

- End plates, item 2

- Bolts, item 3

- Plugs, items 4, 5, 8, 12

- Pistons, items 4, 6, 8, 9

- Tension and compression rods, items 7, 10, 11 


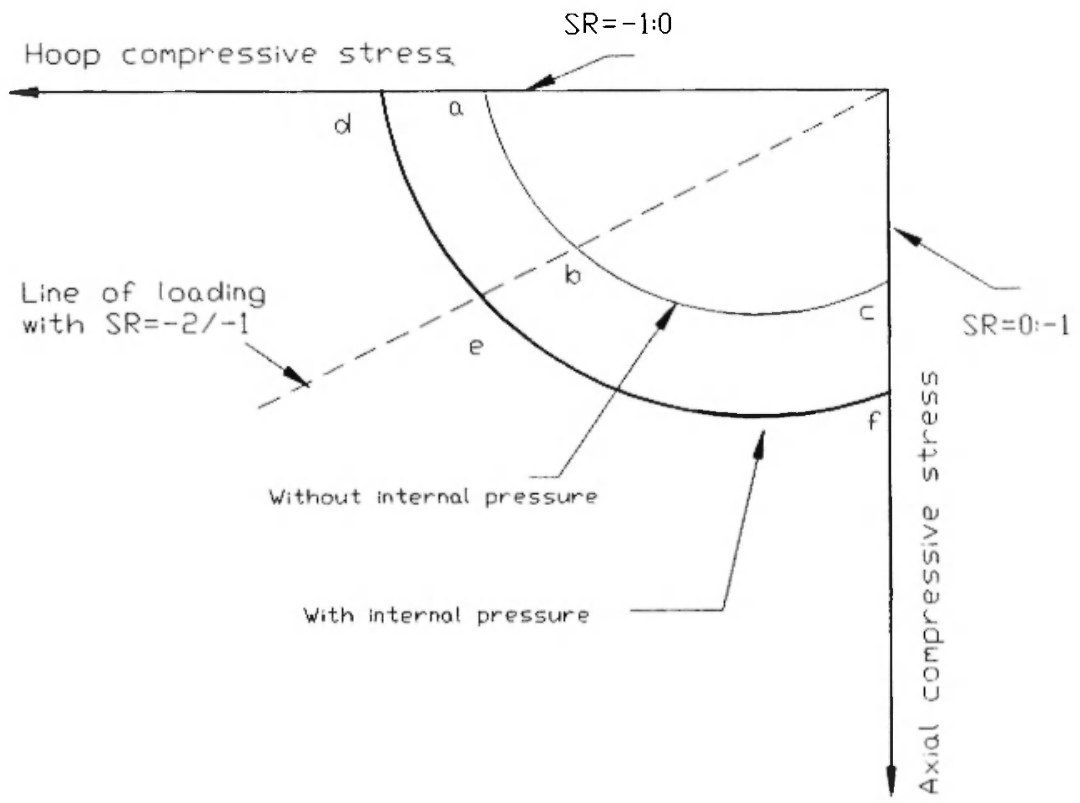

Fig. 1: Schematic diagram of the compressive-compressive failure envelope.
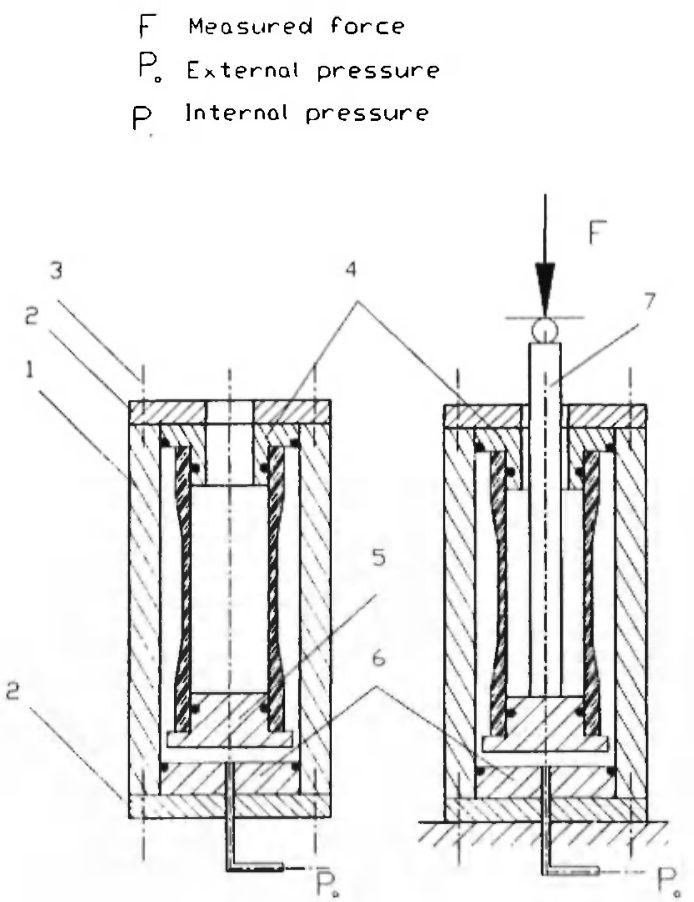

(a)

Closed end burst test Tests with SR between $(\mathrm{P} P=-2 /-1)$ $-10 /-1$ orid $-2 /-1$

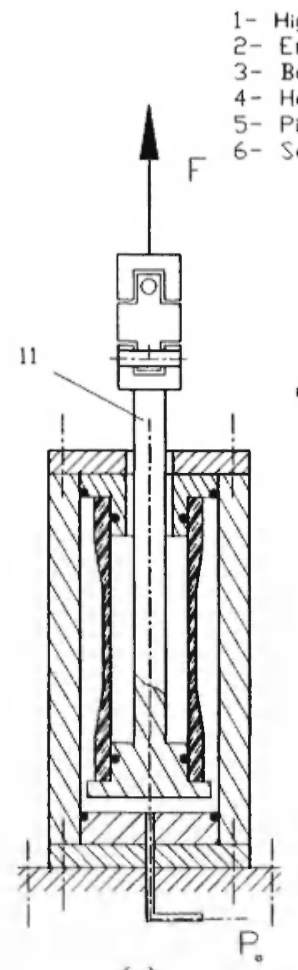

(c)

Tests with SR between $S R=-2 /-1$ and $0 /-1$

Tests with external pressidre aried rid compressiran

7- Compression Rod 8- Plug

9- Hollow end plug

10- Compression Bar

11 - Tension Rod

12- Piston 


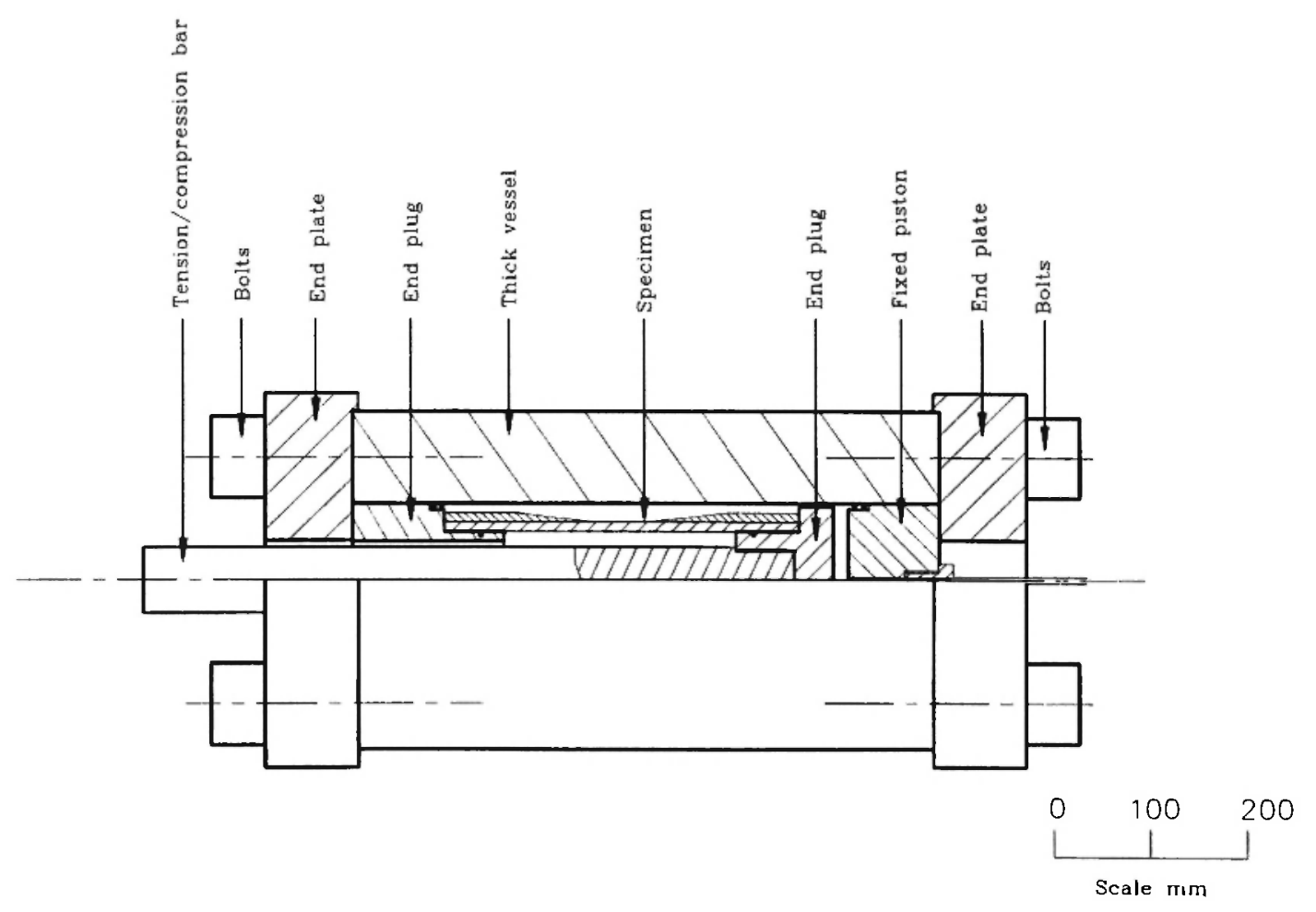

Fig. 3: A drawing showing a section of the rig used for biaxial compression tests of tubes.

Other equipment involves:

- De-intensifier

- High pressure generator

- Testing machine to apply axial load

- Control unit

- Instrumentation and recording systems.

\section{Thick cylindrical vessel (item 1):}

The vessel employed here (see Fig. 3) is designed to sustain internal pressure of $200 \mathrm{MPa}$. It is $160 \mathrm{~mm} \mathrm{ID}$, $352 \mathrm{OD}$ and $610 \mathrm{~mm}$ long and made of $817 \mathrm{M} 40$ steel heat-treated to $277 / 321 \mathrm{BHN}$ giving a a yield stress of at least $800 \mathrm{MPa}$. The inside surface was honed to give a good surface finish. Eight threaded holes were machined in each end of the vessel.

\section{End plates (item 2):}

These are $96 \mathrm{~mm}$ thick plates made of steel. They are bolted to the two ends of the vessel. The plates have a central opening which provides access for the push and pull bars and other pipes and fittings.
Bolts (item 3):

These are M56 bolts grade 12.8. A total of 16 bolts were used ( 8 bolts at each end of the vessel).

\section{Plugs (items 4, 5, 8, 12):}

These are used as tube end closures. The ends of specimens were fitted onto these plugs and seals were inserted into suitable grooves to prevent leakage. The shapes of the plugs were machined in such a way as to minimise end failure and stress concentration following the method discussed in Ref. /20/. For this part of the work, a finite element analysis was carried out to obtain an optimal shape of the plugs /19./.

Pistons (items 4, 6, 8, 9):

These are stationary and are equipped with high pressure seals (Shamban Seals, Denmark) to prevent leakage from the two ends of the vessel. Suitable holes and fittings were made for strain gauge wiring to pass through and for inlet and outlet of the pressurising oil. Items 4 and 8 are combined pistons and specimen end plugs. 


\section{Testing machines:}

Several testing machines which are suitable for applying the required axial tensile or compressive loads are available at our laboratory. Their load capacities range from $200 \mathrm{KN}$ to $3000 \mathrm{KN}$. Some of these machines are equipped with a feed-back system which is suitable for automatic control.

\section{De-intensifier:}

The function of this unit is to produce a constant pressure ratio. As shown schematically in Fig. 4(a), the de-intensifier consists of (i) a low pressure cylinder with a piston of diameter $\left(D_{i}\right)$, (ii) a high pressure cylinder with a smaller piston of diameter $\left(\mathrm{d}_{1}\right)$, (iii) intermediate cylinder at atmospheric pressure and (iv) a set of pipes, isolating valves, relief valves and burst discs, see circuit in Fig. 4(b). The ratio of the pressure $P_{0}$ at the inlet of the high pressure cylinder to the pressure $P_{i}$ at the outlet of the low pressure cylinder is the ratio of the cross-sectional areas of the inner

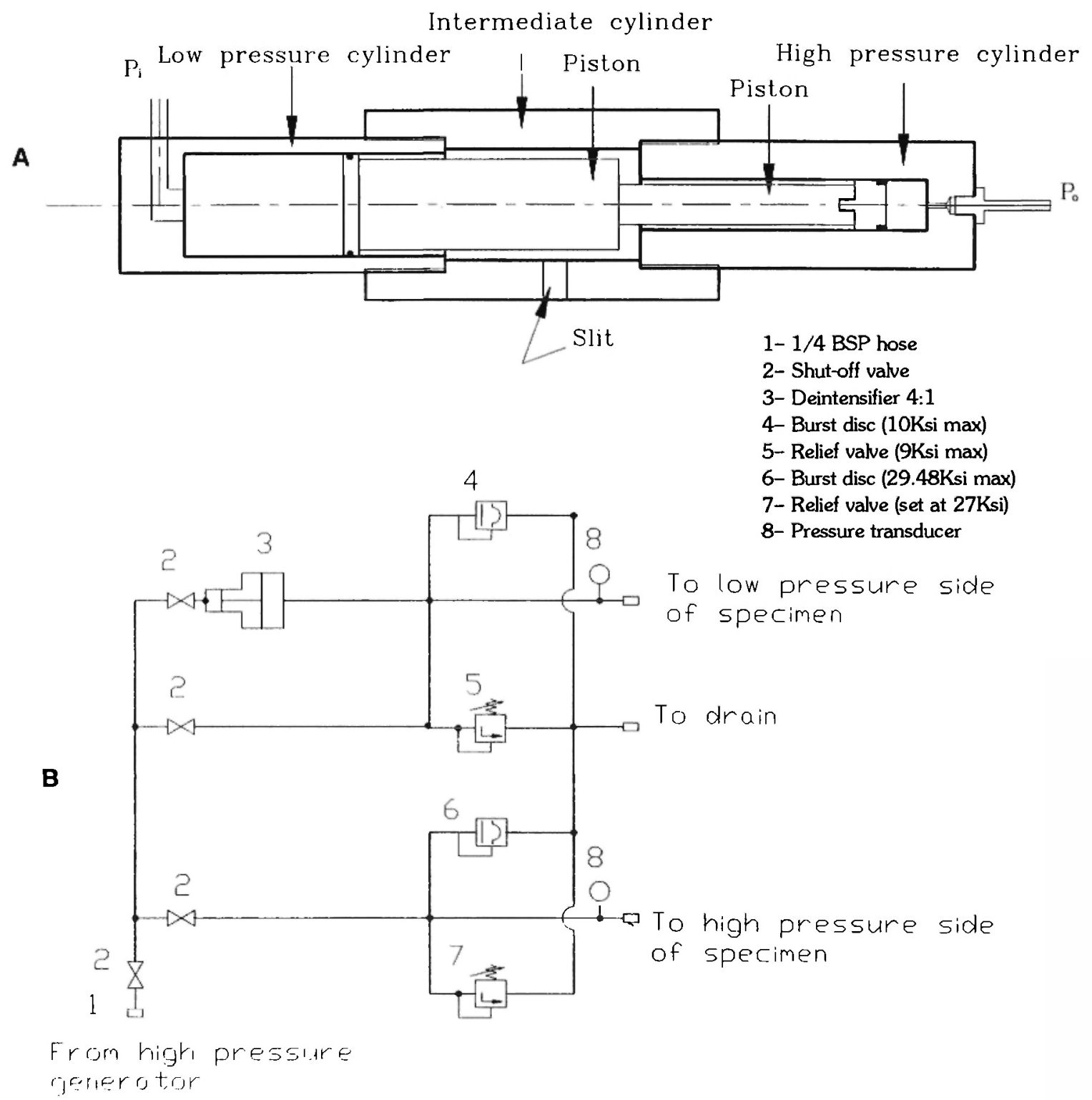

Fig. 4: (a) A schematic diagram of the de-intensifier.

(b) A schematic of a hydraulic circuit used with the de-intensifier. 
surfaces of the two cylinders, i.e., ignoring seal forces $P_{o} / P_{i}=\left(D_{i} / d_{i}\right)^{2}$. A single pressure ratio of $P_{o} / P_{i}=4 / 1$ is used here. However, other pressure ratios can be easily achieved by replacing the low pressure cylinder by another one with a suitable inner diameter.

The low pressure cylinder is a commercial one with a design pressure of $70 \mathrm{MPa}$, while the high-pressure cylinder was made of $17 / 4 \mathrm{PH}$ stainless steel and was designed to sustain pressure of $200 \mathrm{MPa}$. The piston of the high-pressure cylinder and intermediate cylinder which was machined to link the two other cylinders were each designed to carry an axial load of $160 \mathrm{KN}$ at the maximum design pressure. A longitudinal slit was made in the intermediate cylinder to allow the piston position to be observed.

The pipes, stop valves, high pressure tubing and fittings used in making the de-intensifier were chosen to sustain a design pressure of $200 \mathrm{MPa}$ and supplied by Hydratron Ltd., Cheshire, U.K. The main components include:

- A high-pressure relief valve, with an adjustable range of 70-200 $\mathrm{MPa}$,

- A low-pressure relief valve, with an adjustable range of $0-70 \mathrm{MPa}$.

- A high-pressure rupture disc, set at $200 \mathrm{MPa}$, was installed in series with the high-pressure relief valve, and

- Another rupture disc, set at $70 \mathrm{MPa}$, was also installed in series with the low pressure relief valve.

The location of the pressure relief valve and bursting disc and the arrangement and strength of the lowpressure fitting should be designed to avoid failure if the low-pressure circuit is accidentally connected to high pressure (e.g., when the specimen ruptures).

\section{High-pressure generator}

A standard high-pressure generator was assembled to generate pressures up to $300 \mathrm{MPa}$. Basically, it consists of an air-driven mechanical pump, a single acting pressure intensifer, an oil reservoir, oil filter, control valves, check valve, safety relief valve, tee and elbow connectors, high-pressure tubing, air regulator and pressure gauges. All these components were supplied by Hydraton, Cheshire, U.K.

\section{Control units}

The function of these units is to control the ratio of applied stresses so that specific stress ratios are achieved in each test. The de-intensifier circuit shown in Fig. 4 is used to control the internal pressure and external pressure. To control the external pressure and the axial force delivered by the machine, two different arrangements, Figs. 5(a) and 5(b), are used for automatic and manual control. In the automatic case, Fig. 5(a), the pressure transducer was connected to a Fylde amplifier, whose output voltage is proportional to the pressure applied. The output voltage fed into the feedback system of the testing machine which controls the axial force will be proportional to the applied pressure. The slope of the axial force against pressure display line depends upon the stress ratio sought. The slope of the axial force against pressure display line depends upon the stress ratio sought.

In cases where the feedback system is not available, the control is carried out manually by an operator, Fig. 5(b). A predetermined line is drawn on a chart recorder. Then, as the pressure increases, the cross head of the machine is driven by the operator to follow the predetermined line. The resulting relationship between the pressure and the axial load is in the form of a stepped line rather than a straight line.

\section{Instrumentation and recording system:}

The deformations of the specimens are measured using electrical strain gauges (Techni Measurement type YFLA-5 and FLA-3-23) bonded to the inner and outer surfaces of the specimen. Pressure transducers (Intersond type GX 22) having a maximum range of $200 \mathrm{MPa}$ are used to measure the internal and external pressures. When the machines were used, the load was measured by the load cell provided with the machine.

Readings of the pressure, strain gauges and load cell were monitored using a commercial data acquisition device (Solartron) and the data monitored were transmitted to a personal computer ( $\mathrm{PC}$ ) via its $\mathrm{RS} 232$ port. The raw results were saved in floppy discs for further manipulation and analysis. 


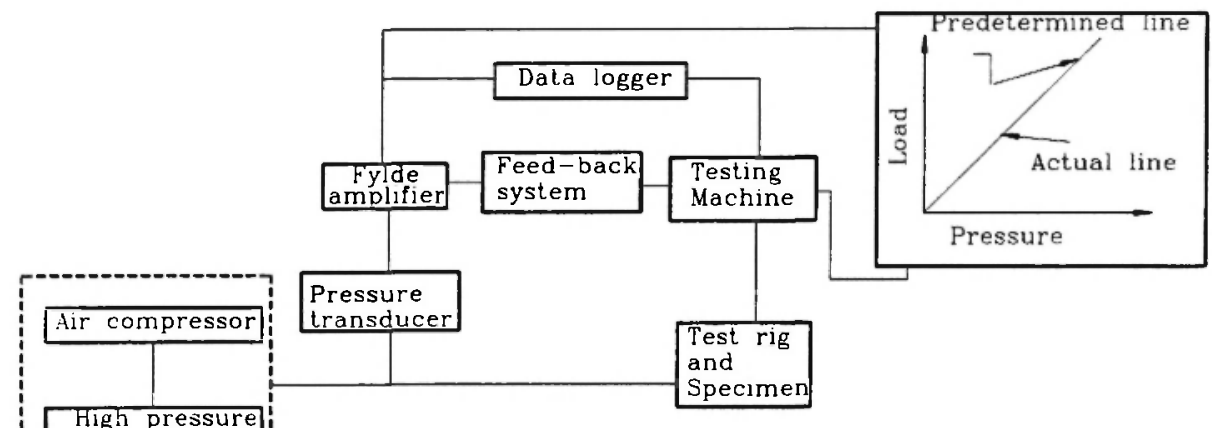

(a) For automatic control testing

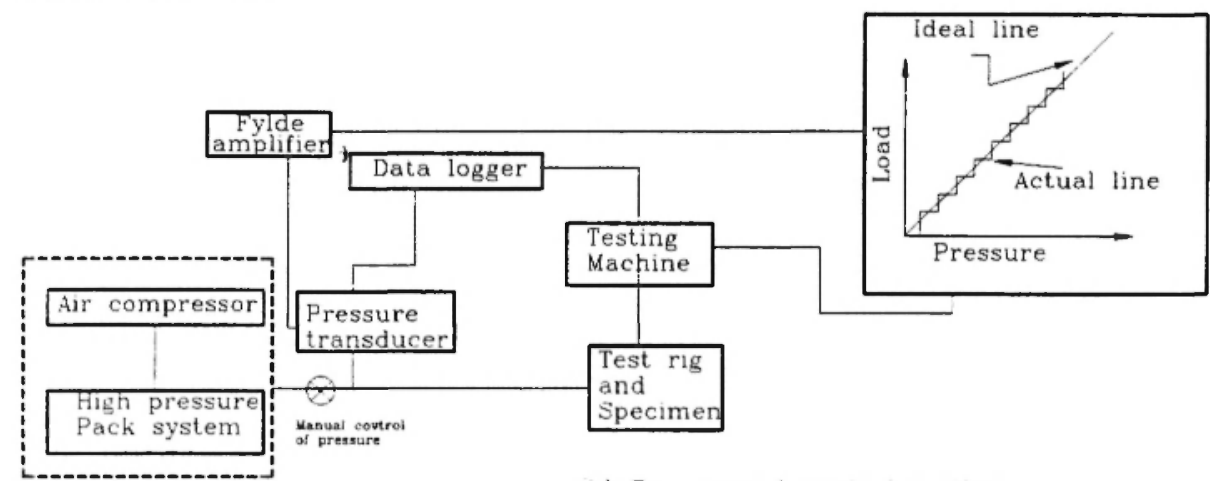

(b) For manual control testing

Fig. 5: Schematic of the control circuit used for testing tubes

(a) for auto feed back system

(b) for manual control.

Circumferential stress MPo

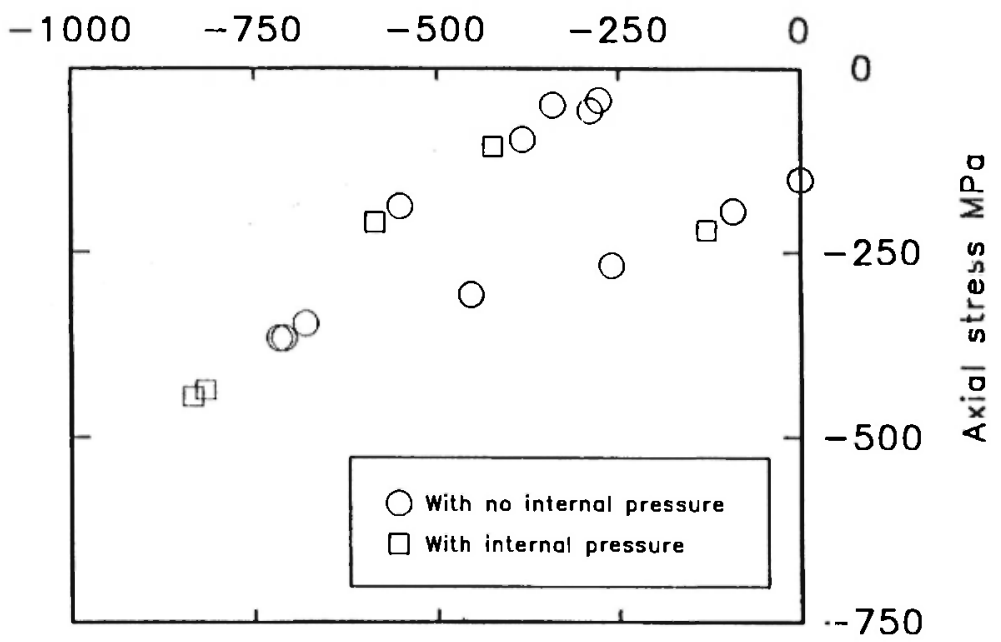

Fig. 6: Experimental circumferential and axial failure stresses of $\pm 55^{\circ}$ E-glass/epoxy tubes under biaxial and triaxial compression. The circles represent the failure stresses under combined internal pressure and axial compression and the squares represent the failure stresses under combined external pressure, internal pressure and axial compression with an external to internal pressure ratio of $4: 1$. 


\section{OPERATION OF THE RIGS}

\section{Biaxial Tests}

External pressure (closed end burst) tests:

The test arrangement is shown in Fig. 2(a) and involves applying equal external radial and end pressure giving $\mathrm{SR}=-2 /-1$. The specimen is held between two plugs: item 4 , which is stationary, and item 5 , which is free to move. An end piston (item 6) sealed the end cavity. The end cavity and the cavity around the outside of the specimen were connected through clearance between the plug (item 5) and the vessel inner surface. The oil was pumped through a hole in the end piston (item 6). An arrangement was made in the piston (item 4) to allow the strain gauge wires to be passed out of the pressure vessel.

\section{External pressure with axial compression tests:}

Fig. 2(b) shows a schematic of the arrangement for these tests. This arrangement is meant to achieve tests between points "a" and " $\mathrm{b}$ " in Fig. 1. A testing machine is used to counteract some or all of the axial load generated by the pressure acting on plug (item 5). The axial load is applied through the push-bar (item 7). A ball bearing is used to eliminate any misalignment or bending.

\section{External pressure and axial tension tests:}

This arrangement, Fig. 2(c), is to achieve failure stresses between points " $b$ " and "c" of the failure envelope shown in Fig. 1. The testing machine is used to increase the axial compressive stress, applied to the specimen through the pull-bar (item 7). During the tests, the vessel is bolted to the base of the testing machine and the ball is replaced by a universal joint which minimises any bending and misalignment between the centre of the pull-bar and the machine. The axial tension load is kept proportional to the external pressure to ensure a constant stress ratio, SR.

\section{Triaxial Tests}

To introduce a through-thickness stress component, tests are carried out to achieve failure points at and between points " $d$ ", " $e$ " and " $f$ " in Fig. 1. These types of tests involve applying internal pressure, external pressure and axial load. The ratio of the internal pressure/external pressure is kept constant in the tests. The mechanism for control!ing these two pressures is shown in Fig. 4.

Combined internal and external pressure with $S R=$ $-2:-1:$

The rig shown in Fig. 2(d) is rearranged as shown in Fig. 3. The plug (item 8) is machined to allow pressure $P_{1}$ to be introduced to the inside of the specimen. No testing machine is required.

Combined internal and external pressures and axial load:

A testing machine is required to apply axial load through the bar, item (10) in Fig. 2(e). The relationship between the applied axial load and external pressure can be simplified by making the diameter of the loading column, item (10), equal to the inner diameter of the specimen.

\section{EXPERIMENTAL RESULTS}

Tests have been carried out on $\pm 55^{\circ}$ filament-wound angle-ply E-glass/epoxy tubes of $100 \mathrm{~mm}$ and $51 \mathrm{~mm}$ diameters and overall lengths up to $400 \mathrm{~mm}$. The tubes had a range of wall thicknesses giving values of $R / h$ down to 3 . The winding angle is measured between the fibre direction and axial direction of the tubes. The tubes were reinforced at both ends and were tested under all the various types of loading described above.

The specimens were fitted with electrical resistance strain gauges on the inner and outer surfaces.

Figs. 7(a) and (b) show circumferential strains measured at the inside and outside surfaces at three different positions around the circumference near the centre of the gauge length of two different tubes. Both tubes were $100 \mathrm{~mm}$ internal diameter but they were of different wall thicknesses.

In both cases the test arrangement was as shown in Fig. 2(a) which gave $S R=-2:-1$ and the strain readings are plotted against the applied external pressure. 


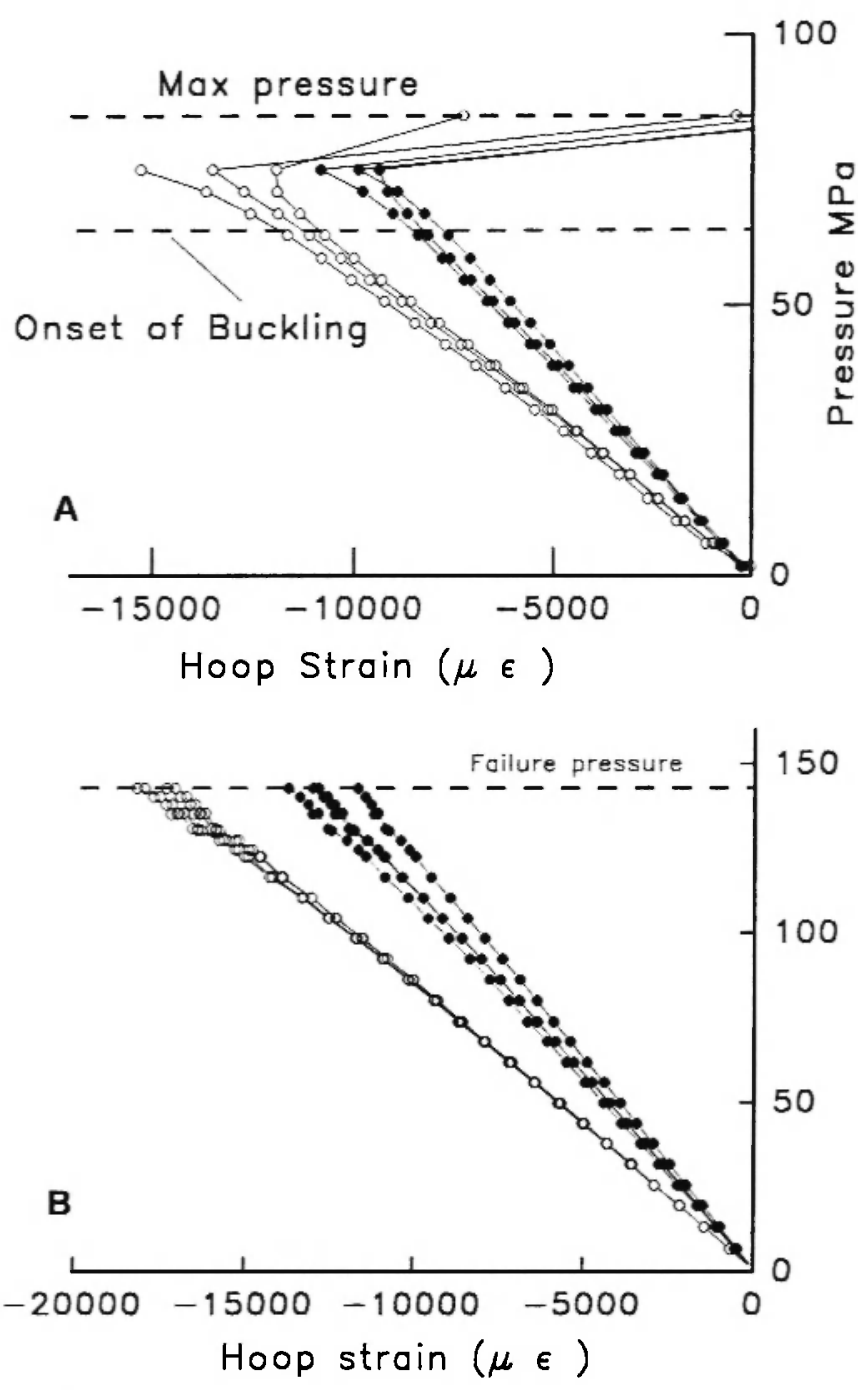

Fig. 7: Measured pressure versus hoop strain curves for $\pm 55^{\circ}$ E-glass/epoxy $100 \mathrm{~mm}$ diameter tubes tested under a strain ratio of $\mathrm{SR}=-2 /$ -1 for two cases of failure: (a) Failure by buckling of a $9.5 \mathrm{~mm}$ thick tube, and (b) Failure by crushing of a $14.5 \mathrm{~mm}$ thick tube. (Note that open symbols represent the inside strains and the solid symbols represent the outside strains.)

The results follow the expected pattern with the internal strains slightly greater than the external strains as discussed in detail elsewhere $121 \%$. Of particular interest here is the behaviour at high pressure and its relevance to the identification of the mode of failure.
For safety reasons, bearing in mind the extremely high pressures (up to $200 \mathrm{MPa}$ ), the operator was not allowed to approach the rig during the tests so visual observation of the behaviour of specimens was not usually possible during the tests. Failure was detected by an abrupt drop in pressure accompanied usually by a loud bang. An abrupt drop in pressure can be associated with failure by buckling or by fracture (crushing).

Shell buckling occurs in thinner walled tubes and is accompanied by wide divergence between readings from strain gauges on the inside and outside surface of the tubes, as indicated just before maximum pressure in Fig. 7(a) for a specimen of $9.5 \mathrm{~mm}$ wall thickness.

In tubes that failed by crushing the strain readings on a given surface were similar (i.e., did not diverge) right up to fracture as shown in Fig. 7(b) for a $14.5 \mathrm{~mm}$ thick tube. After failure these specimens had the appearance shown in Fig. 8(a) with clear fractures running parallel to the fibres.

Figure 6 shows failure stresses for the $\pm 55^{\circ}$ filament wound E-glass epoxy tubes under various combinations of circumferential and axial compression. The results shown by circles were obtained using the test arrangements shown in Figs. 2(a)-(c) with no internal pressure applied. The results are discussed in detail elsewhere by Kaddour et al. $/ 21 /$ and have been compared by Hinton et al. $122 /$ with failure stresses for similar tubes subjected to a wide range of loading conditions, including circumferential tension combined with axial tension and compression obtained by Soden et al. $/ 23 /$.

Also shown in Fig. 6 are results (square symbols) of five tests under triaxial compression obtained using the test arrangements shown in Figs. 2(d) and (e). The ratio of external pressure to internal pressure was maintained at $4: 1$ throughout these tests. All these specimens had $\mathrm{R} / \mathrm{h}$ ratios of approximately 5.4 .

All failure stresses shown in Fig. 6 were calculated for the inside surface of the tube using thick orthotropic cylinder theory $121 \%$. All the specimens failed by fracturing with characteristics similar to those shown in Fig. 8(a) and (b).

The addition of internal pressures (of magnitudes up to $40 \mathrm{MPa}$ which are small compared with the applied circumferential stresses) resulted in a noticeable increase in effective circumferential and axial strength compared with the results at the same ratio of in-plane 
(a)

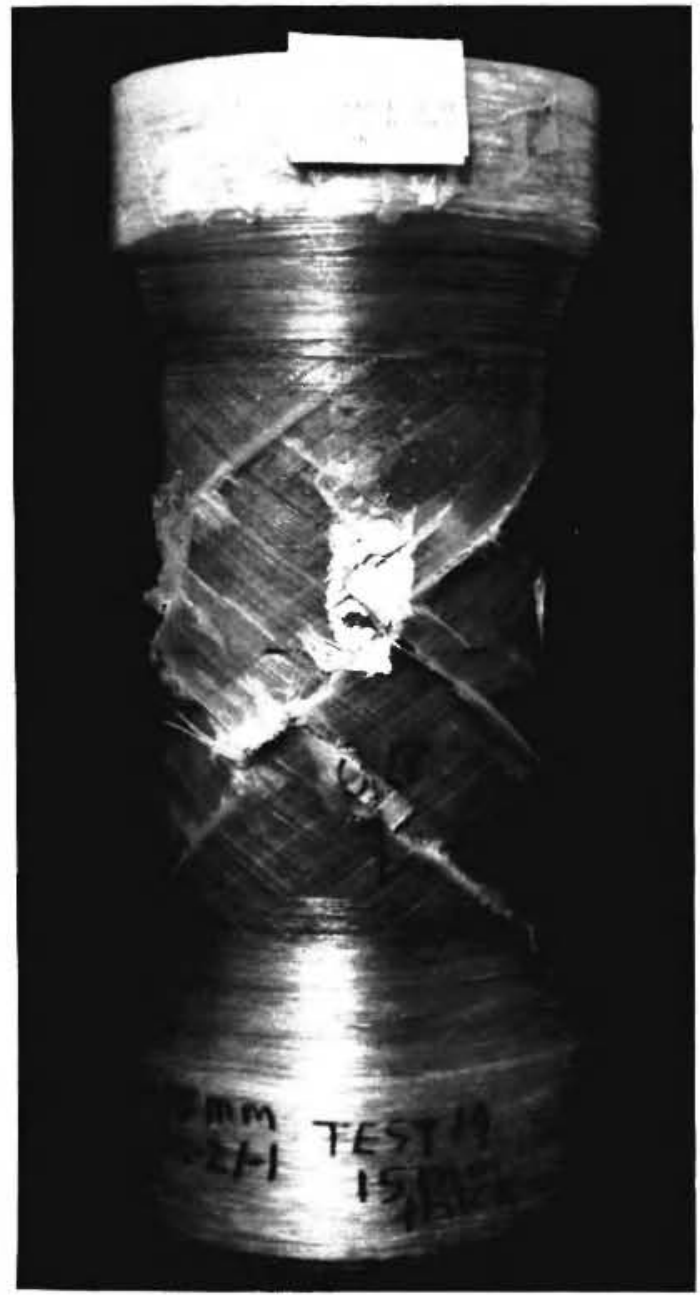

(b)

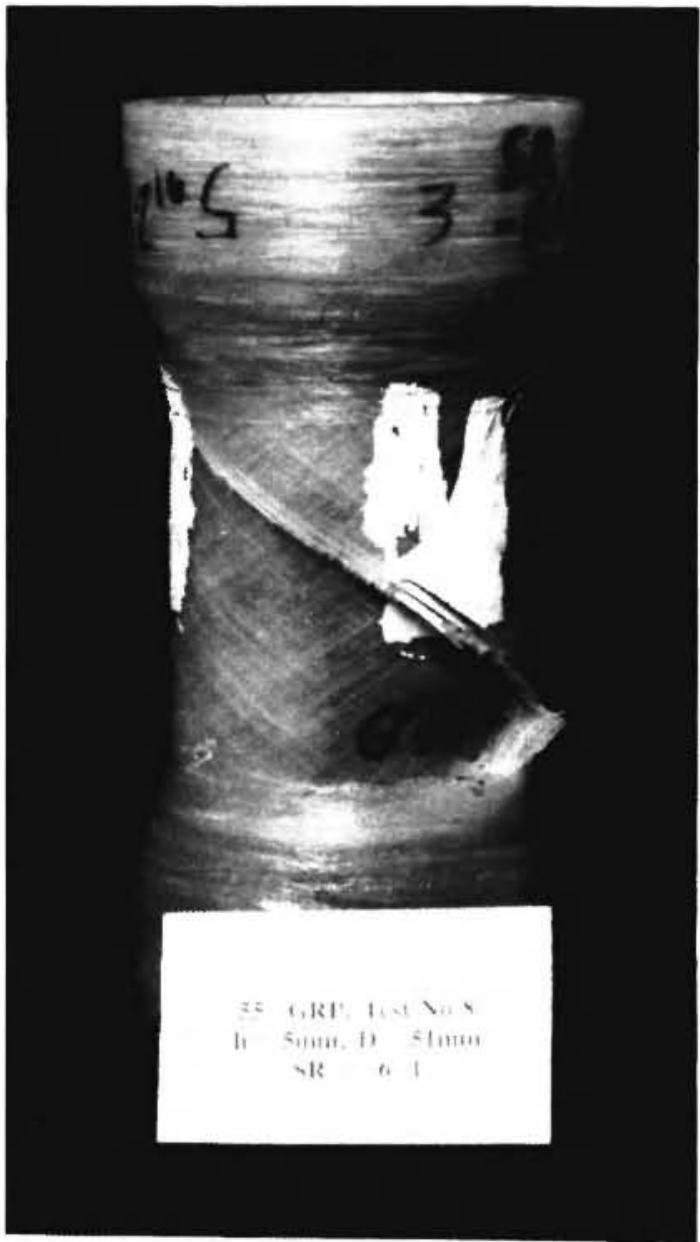

Fig. 8: Typical failed specimens tested under biaxial compression:

(a) $100 \mathrm{~mm}$ diameter, $15 \mathrm{~mm}$ thick specimen tested under $\mathrm{SR}=-2 /-1$.

(b) $51 \mathrm{~mm}$ diameter, $5 \mathrm{~mm}$ thick specimen tested under $\mathrm{SR}=-6 /-1$.

compressive stresses but with no internal pressure applied.

\section{CONCLUSIONS}

A multi-purpose test rig suitable for testing tubular specimens under combined external pressure up to 200 $\mathrm{MPa}$ (with and without internal pressure) and axial loading has been described. The rig was successfully used to determine the strength of \pm filament-wound, $E$ glass fibre-reinforced epoxy tubes under a range of biaxial compressive stress filed by applying combined external pressure and axial compression. The rig was also used to carry out triaxial compression tests in which through-thickness compressive stress components were introduced by imposing a differential pressure across the thickness of the tubes. The additional radial compressive stresses increased the effective in-plane compressive strength of the tubes.

\section{ACKNOWLEDGEMENTS}

The work reported here was sponsored by the Defence Research Agency (DRA), Fort Halstead, United Kingdom. 


\section{REFERENCES}

1. S.R. Swanson and Y. Qian, Compos. Sci. Struct., 43, 197-203 (1992).

2. P.D. Soden, R. Kitching, P.C. Tse, Y. Savalas and M.J. Hinton, Compos. Sci. Tech., 46, 363-378 (1993).

3. U. Hütter, H. Schelling and H. Krauss, in: Failure Modes of Composite Materials With Organic Matrices and Other Consequences on Design, NATO, AGRAD, Conf. Proc. No. 163, Munich, Germany, 13-19 October, 1974.

4. M.F.S. Al-Khalil, M.Sc. Dissertation, Mechanical Engineering Department, UMIST, UK, 1986.

5. H.J. Garala, in: Proc. 1987 SEM Spring Conference on Experimental Mechanics, Houston, TX, 14-19 June, 1987; pp. 948-951.

6. S.R. Swanson and G.E. Colvin, Compressive strength of carbon/epoxy laminates under multiaxial stress, Final Annual Report to the Lawrence Livermore National Laboratory, UCRL21235, 1989.

7. L.V. Smith and S.R. Swanson, Composite Materials and Structure, AD-37/AMD-179, 285296 (1993).

8. J. Mistry, A.G. Gibson and Y.S. Wu, Compos. Struct., 22, 193-200 (1992).

9. C.W. Weaver and J.G. Williams, J. Mater. Sci. 10, 1323-1333 (1975).

10. T.V. Parry and A.S. Wronski, J. Mater. Sci., 17, 893-900 (1982).

11. R.H. Sigley, A.S. Wronski and T.V. Parry, Compos. Sci. Technol., 43, 171-183 (1992).
12. H. Couque, C. Albertini and J. Lankford, $J$. Mater. Sci. Lett., 12, 1953-1957 (1993).

13. J. Lankford, Compos. Sci. Technol., 51, 537-543 (1994).

14. E.S. Shin and K.D. Pae, J. Compo. Mater., 26, 828-868 (1992).

15. E.S. Shin and K.D. Pae, J. Compo. Mater., 26, 462-485 (1992).

16. Y.J. Jee and S.R. Swanson, Trans. ASME, J. Engg. Mater. Technol., 117, 347-350 (1995).

17. L. Kroll and W. Hufenbach, in: Proc. ICCM-10, held in Whistler, BC, Canada, 14-18 August, 1995, Vol. I, A. Poursartip and K. Street (eds.), Woodhead Publishing Company, Cambridge, England, 1995; pp. 715-722.

18. J. Highton and P.D. Soden, J. Strain Analysis, 17, 31-43 (1982).

19. W. Liu, P.D. Soden and A.S. Kaddour, "Design of end fittings for composite tubular test specimens subjected to external pressure loading", in preparation.

20. R.J. Miller, in: Composite Materials: Testing and Design, ASTM STP 460, 1969; pp. 150-159.

21. A.S. Kaddour, P.D. Soden and M.J. Hinton, "Failure of $\pm 55^{\circ}$ glass/epoxy filament wound tubes under biaxial compression", in preparation.

22. M.J. Hinton, P.D. Soden and A.S. Kaddour, in: Proc. ICCM-10, held in Whistler, BC, Canada, 14-18 August, 1995, Vol. I, A. Poursartip and K. Street (eds.), Woodhead Publishing Company, Cambridge, England, 1995; pp. 63-72.

23. P.D. Soden, R. Kitching and P.C. Tse, Composites, 20 (2), 125-135 (1989). 